\title{
THE
}

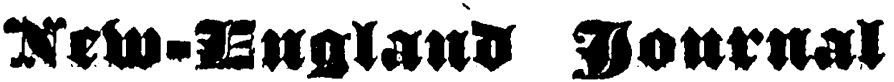

OF

\section{MEDICINE AND SURGERY.}

7.91. XI7.]

TANOARY, 2886.

[No. I.

The Practical History of a New Epidemical Eruplioe Miliary Fever, with an Angina Ulcusculosa, which prevailed in Nerw-England in the Fears 1735 and 1736.By Wiluiam Dougrass, M.D.*

NHIS Distemper did emerge 20th May, 1735 in Kingston 1 Township 50 Miles Eastward from Boston; it was no foreign importation, Kingston being an inland place, of 'no Trade or considerable communication. The first seized was a child who died in three Days Illness; about a Week thereafter in another Family at four Miles distance, three Children were seized successively, and died also the third Day it continues spreading gradually in that Township, seizing here and there particular Families with that degree of violence, that of the first circiter forty decumbents none recovered as we were informed. It was vulgarly called the Throat Illness, or a Plague in the Throat, and alarmed the Provinces of $\mathcal{N}$ ewEngland very much. Some died of a sudden or acute $\mathcal{N}_{e-}$ crosis; but most of them by a Symptomalick affection of the Fauces or Neck; that is by Sphacelations or corrosive Ulcerar tions in the Fauces, or by an infiltration and tumefaction in the

- Buston N. E. Printed by Thomas Fleet 1736. We have been requested to republish this Essay, which is, we believe, enticely out of print. Wo to it vary readily from our beliaf in its value, as it has been pronounced by campeteat judses one of the bęst works extant upon the subject of which it treate-tor.

VOJ ILIV. 
Chops and fore part of the Neck, so turged, as to bring all upon a level between the chin and stermum, occasioning a strangulation of the Patient in a very short time.

After a few Weeks it spreads into the neighbouring Townships, but with more mildness. The first appearance that we can recollect of it in Boston, was 20th August on a Child of Capt. Stannys at the North End; having white spccks in the Throat, and a cutaneous efflorescence: A few more in the same Neighbourhood were seized in like manner, about the same time. Towards the end of September it appeared in several parts of the 'Town, with a complaint of soreness in the Throat, Tonsils swelled and speckt, Uvula relaxed, slight Fever, flush in the Face, and an Erysipelas like efflorescence on the neck, chest and extremities; but being of no fatal or bad consequence, nothing more than a common cold was suspected. Our first alarm was from a young man How At. 20 in the beginning of October: His History runs thus; He was lately arrived from Exeler to the Eastward, where his Brother died of this lllness; his Symptoms were great prostration of Strength, 2 speck in one of the Tonsils, colliquative Sweats, Pulse not high and full, but low, hard, stringy, unequal and more frequent than natural, deglutition good to the last, no Sphacelation in the 'Throat, no eruption; from a rash inconsiderate opinion of forcibly quelling the Malignity, he was thrice let Blood, had some Emeticks and Catharticks administered, and by profuse evacuations was gradually reduced, so as to die of ia gentle decay of natural Strength, the 6th Day of Illness.

Beginning of $\mathcal{N}$ ovember it spread considerably in Boston, estpecially amongst Children, with more violent Symptoms, and scverals die of it in various Periods: it seemed to be at the hight, as to Numbers ailing and quantity of Deaths, the second Week of March; that Week there were 24 Burials, whereas communibus annis in that Season they are only 9 or 10 per Week.

It is generally in so considerable a degree more favourable in Boston, than in the Townships where it first prevailed; that many can scarce be persuaded of its being the same Distemper: It is nevertheless essentially the same, there is no Symptom, even the most malignant that has appeared in $\mathcal{N}$ ewHampshire, but what the like has occurred in Boston. Perhaps Boston dry healthy air, good feeding, constitutions less Psorick, and the better management of the Sick, favoured us; the reasons for its proving more mortal in the other Towns, may be, the Country woodland and fresh water damps, (the Sheep in fenny lands are most susceptible of and suffer most by the Rot)

The New England Journal of Medicine, Surgery and Collateral Branches of Science as published by 
their coarse Food, salt Pork diet, Psorick Constitutions, (which is one of the principal Endemial distemperatures in Nezv-England) bad Lodgings, and that Mischievous Practice of using this Distemper with profuse evacuations, whereby the laudable and salutary cuticular eruption has been so perverted as to be noticeable only in a few, and in these it was called a Scarlet Fever; the great prostration of Strength essential to this Distemper is so much increased, as to render Nature an under match for the assaults of this lliness and its consequences. In fact to the Eastward in some Country Towns, at certain times have died 1 in 3 of the Sick, in others 1 in 4, in scarce any fewer than 1 in 6 , whereas in Boston not above 1 in 35 have died.

As in most Epidemical acute Illnesses, especially eruptive Fevers, (witness the Small Pox) so in this, are very many varieties or degrees, from the mosi gentle and benign to the most malignant. Symptoms did vary chiefly from something inscrutable in the Constitutions of Families and Persons; the Scropholous and Psorick were the most susceptible of it, and did suffer most by it; the Regimen had a considerable influence, here some who might have survived the natural Symptoms did succumb by profuse U. S. and other evacuations, one of the most essential Symptoms of this Distemper (as before hinted) being great prostration of Strength. In so great variety it is not possible to give any concise scholastick description, which may comprehend all: We shall therefore, as a Standard first describe the most frequent sort, as it appeared in good constitutions.

A previous listlessness, and languishing countenance for a Day or two, or some other pronuncia as u. g. wet Nurses loosing their Milk. The first attack is somewhat of a chill or shivering; soon after follows head ake or some other versatile spasmodick pains, as pain in the back, joints, side, \&c; a vomiting or nausea, or in some constitutions which are not easily provoked to vomit, only a certain uneasiness or sickness at Stomach; at the same time the Uvula but chiefly the Tonsils were tumified, inflamed and painful, with some white spects; then follows a flush in the Face and some miliary cruptions there, with a benign mild Fever, the same efflorescence soon after appears on the neck, chest and extremities; the 3d or 4th Day, Eruption is at the hight and well defined with fair intervals; the flushing goes off gradually, with a general itching; and in a day or two more the cuticle scales or peels off, especially in the extremities: At the same time the cream coloured sloughs or specks in the Fruces bersmm

The New England Journal of Medicine, Surgery and Collateral Branches of Science as published by 
loose and cast off, and tumefactions there do subside. The tongue from the beginning is fur'd as in a Mercurial plyalism, urine high coloured, Blood by U.S. more florid than natural, in the whole course of the distemper a very great prostration of Strength, and faintness upon recovery, nervous pains and weakness in the joints, particularly in the neck, wrists and ancles; universal tenderness to the touch; a tickling guttural cough, some short Hertick flushings, and loss of en bon point. As in the Measles there is a peculiar smell, so in our Distemper the effluvia from the Patient have a proper smell; in Children as if troubled with Worms, in grown Persons the rancid smell of foul Bed Linnen. The alvine excrement is of a dark cast and very fetid.

This Standard kind when left to nature, with a warm soft Regimen, had generally an easy and salutary course in six or seven days; but when by a hot cordial method, or on the other extreme, by being too much exposed to the cold, or by officious profuse tvacuations Nature was disturbed in her Work ; the Distemper was protracted, or some consequential ails from an imperfect defecation ensued.

Where Nature required any assistance, the principal intentions were with regard to the cuticular eruption and the ulcuscula in the Throat. Any Affection of the Throat does frequently produce a natural.ptyalism: Mercurials used with discretion are a kind of specifick in such like ulcers and ulcuscula, and in fact here they moistned the Throat and Mouth, stopt the spreading of the ulcuscula, and promoted the casting off of the sloughs; and as an accessory advantage (the Patients being mostly Children) destroy'd Worms : amongst all its preparations Calomel answered best, the gentle vomiting or few stools that it occasioned in some, did not confound the natural course of the Distemper: Turbith proves generally too strong a revulsion, and the Eruption is thereby too much diverted; this Distemper did not well bear any other evacuations but Mercurials. Any detergent Gargle, with an addition of the Tincture of Myrrh and Aloes, was of good use, especially for the Ulcuscula, and did promote the discharge of a ropy Phlegm lodged in the Fauces. As to the cuticular efflorescence, it was not a scarlet suffusion, but a miliary palpable eruption, or in lieu thereof in some constitutions a continued gentle breathing Sweat; and in a very few, who have naturally a liberior transitus by the Pores than is usual, no sensible cuticular excretion; in all the morbid effluvia discavered themselves by their peculiar smell: These were with good effect sollicited by Snake-raot Tea; or (as in some Per- 
sons) where this did occasion an ardor or burning heat, instead of a breathing mellow Sweat, Sp. C. C. or any other volatile Spirit in small Herh Tras answered well. Blistere and Suppedanca, in the beginning where Symptoms were not violent, occasioned a protracted Eruption; in some inmediater ly upon their application, the Eruptions vanished or became less vivid. When the Fruption began to decline a few loose Stools were very refreshing. The Patient being up, and having recovered a competent degree of Strength, is to be purged once or twice, to carry off any feculency that may have remained in the Blood and Juices.

For a more distinct conception of the varieties in this Distemper, they may be reduced to three Classes.

1. Those who die the first, second and third day of Illness, by an irremediable $\mathcal{N}$ ecrosis of the Oeconomy: in sucb the Seizure is generally sudden, a sinking pain at the Stomach, an extreme prostration of Strength, a titubating low pulse, in some a stupor, in others a delirium, in some children convulsions, and all of them generally die dozie: they are attended with some colliquation, as continued vomiting, purging, profuse Sweats, bloatedness of the habit, an infiltration like that of the Aumps vulgarly so called, one or more of these : in general the texture of their blood and juices is much destroy'd and rendred an incoherent puddle of corruption; in fact immediately upon (sometimes before) their exit, they have an intolerable fietor. In this Class U. S. and other evacuations did accelerate death.

II. Those where the distemper has its common or ordinary course; here the 6 or 7 day seems to be critical, and the Symptoms of death or recovery do generally then begin to manifest themselves. Some by peculiarity of constitution, and from improper administrations do die or have an incipicent recovery sooner: others for the like reasons or some particular accidents (u. g. if about the time of regular menstmuation, the complicated fret occasions worse Symptoms, and of longer continuance) have this period protracted and in such (where death is inevitable) the Symptoms of death may continue a day or two longer, that is the Patient may die the eighth or ninth day. All who continue 111 after that period, belong to the third Class, that is of consequential ails.

The Symptoms. of bad Omen in this Class, are very great prostration of strength, dejection and despondency of mind, titubating low pulse, incessant vomitings purgings or sweats, Tonsils much inflamed endangering strangulation, the specks in the Fauces of a brownish or leaden colour. or ragged and 
jagged, a continued jactantia in some, in others a stupor, refusal of assumenda even of diluting common drinks, a dry parched skin, Eruptions appearing and disappearing alternately, Eruption universal of a dark redish cast continuing crude many days (because in this as in all eruptive Fevers, the darker or more livid the efflorescence, the more malignant) where the miliary pustles are large, distinct and pale like a chrystaline Small-Pox; where strong Cordials and Alexipharmicks have been used, the face, eye-lids, arms, hands, legs, feet swell, and are of a dark red complexion, as in the most malignant Small-Pox; in children if the velum Palati be much affected, with an ichorous discharge by the Nose; where many mucous linings are expectorated, resembling the cuticle raised by Vesications; when pus was brought up, where no sloughs or exulccrations could be seen in the Fauces; where without any difficulty in swallowing, this affection has reached diswn the Bronchia unto the Lungs with the Symptoms of a $\mathcal{N} e w-E n g l a n d$ Quinsey, and was erroniously deemed such: the deeper in the Thorax the complaint the greater the danger: in some young children with scarce any appearance in the Throat, spreading Ulcers did form behind the Ears in the place where Infants have a natural Issue or running. In some the Tongue did throw off a slough or Exuvia, retaining the impressions of the Papillæ; being a Mucus inspissated, and of the same nature with those mucous linings expectorated from the Bronchia or Oesophagus. Some have had impostumations in the Fuces, with a fatal strangulation, while others have escaped by the discharge of Ichorous curdly matter. Some especially of the adult female kind, have had Hysterical or Nervous Suffocations; but of no bad consequence, unless officiously and ignorantly treated with U. S. and other evacuations.

The Fever is seldom too high, sometimes it is too low for a thorough laudable Eruption. If the Fever is too high, if the patient is plethorick or accustomed to U. S.; take away some Blood but with discretion; if the Tonsils are much inflamed with great pain and difficulty in swallowing, use U. S. in the Jugulars, Epispasticks ad $\mathcal{N} u c h a m$, encourage the Eruption, or its succedaneum a breathing sweat; a profuse sudor is equally to be avoided as a continued Diarrhoea, either of them confound the distemper in its natural course. In case of colliquations give ol. Cinamomi, decoct. Alb. Elixir Vitriol, torrified Rhubarb and the like. As to the specks or sloughs in the Fauces (they cast of in course in the benign kind) Mercurials inwardly, and the Gargles before mentioned topieally, arc 
useful; the practice in some Country places of separating them forcibly by spatulas is hurtful brcause the irritation occasioned thereby induces a further flux upon the part, and the sloughs form again worse conditioned than before. Where the Brain is affected as in Vigilia, jactantia, delirium, Coma, stupor, \&c; glysters, Vesicatories \& suppedanea are to be used. Where faintness or great prostration of strength, give toasted Bread soaked in some generous Wine and Water, or volatile Spirits in their common drinks; Bczours, Testacea and the like are of no use, the Shop Cordial Juleps and mixtures are only sugar'd drams. 'To cnumerate all the other accidental Symptoms which do happen here, in common with other acute diseases, would be trifling.

1II. Consequential ails, which may be enumerated as in the following articles.

1. The natural Effects of an intense corrosive scorbutick like colliquation of the Blood and Juices. Anasarcous swelling or blotedness of the face, in some to that degree as to shut up the Eyes; the same Oedemelous swellings in the extremities; in a few an Infiltration in the Scrotum, in some Petechice, Purple spots, scorbutick like sugillations upon the least scratch or bruise; hamorrhages of all sorts, by the Nose, from the Lungs in expectoration, by Stool, by Urine, Profluviums in Women tempore non debito; these are dismal phanomina in the state of any acute Fever, u. g. Small-Pox, and scarcc any recover; but in our distemper being only short temporary consequential ails, scarce any of them proved mortal, hut gave way to a soft milk diet, in some to Corlex Peruv. or Elixir Vitrioli in others; a Girl æt. 14. with hæmorrhages of several sorts, with Purple spots, and scorbutick like sugillations, recovered, notwithstanding of a very loose Regimen. N. B. These were not to be attributed to the Mercurial administrations, because they equally happened to those who had taken no Mercury.

2. Where the defecation has not becn complcat, from want of natural strength, or from catching cold, or from undue evacuations: the reliquia were thrown off by Urtications, by Vesicalions in several parts of the Body, by serpiginous eruptions chiefly in the face, by purulent Pustules, by Boils, by swellings and impostumations in the groin, armpits and other parts of the Body. The most frequent consequential ail of this kind is, when from cold received, the glands and cellulary tegument called the panicula adiposa in the fore part of the neck becomes infiltrated and obstructed; if not soon resolved by the continued fotus of warm woollens and hot animating applications; the induration increases and spreads 
every way, so as to suffocate some, in others they sphacelate and becoine Ulcers mortal or of difficult cure: thus a few have died with us in Boston, but many in the Country. By catching cold likeways the Tonsils have afterwards inflamed and come to suppuration: In a young Woman the Tonsils and $U_{v u l a}$ being much ulcerated, did unite and coalesce into one mass and remain so; this might have been prevented by frequent gargling.

While these indurations are only in the form of Kernels as they are vulgarly called, woollen muflers, Empl. de Ranis cum Mercurio and the like, with gentle Calharlicks, soon resolves them. Cataplasms in this case have done much mischief; because so soon as they are become cold, they act as a chilling damp upon the part, and destroy its vitality. When they arrive to the state of putrid flaccid Ulcerations, digestives and soft fomentations intenerate the part and occasion the Ulcer to spread; spirituous animating desiccative dressings have done better. Exposing the part to the cold, either in state of 'Tumefaction only, or in the subsequent exulcerations aggravates the ail.

3. From the violence which the $\mathcal{N}$ erves have suffered in this Illness; even where the Symptoms were apparently mild, they all complain of great faintness and Universal weakness, particularly in the joints. Some Women have Hysterick affections, in a few upon recovery imbecility of mind or silliness, in some stammering or loss of Speech for a few days, some have had short fits of Melancholy, some were seized with Epileptick fits, but not so as to become habitual. All these disorders soon vanished, as the Patient recovered his Strength in course of time, and by the help of a restorative cordial Regimen and diet.

4. Other consequential ails in common with other fevers ; particularly where the Strength of nature has been much impared by the distemper it self, or hy immoderate evacuations, the Patien is left in a languishing weakness. Where the Eruption has been impeded by being exposed to the cold, or by unseasonable. $U . S$. or Catharticks; the patient falls into Hectical wastings, fatal to some in a very short time. All who underwent immoderate evacuations, were a long time in recovering of their Strength.

SCHOLIA or some general remarks upon the whole.

1. This seems to be a new kind of Epidemical disease. It is not the same with the Aphthe which have at times prevailed in Holland, as described by Forestus, and mentioned by Boer. have in his Colleges. Tournefort says there is a distemper 
not uncommon in the Levant, viz a Carhuncle or plague sore in the bottom of the Throat; it carries off children in a few days, but does not affect grown People as does ours. Capt. Morton of late Plymouth Colony, who wrote many years ago his New England Mentorial, says that an. 1650. a disease in the Mouth and Throat prevailed, which proved mortal to many in a short time; but he does not describe it, and mentions nothing of a Fever. In Boston November 1719. a slight miliary fever chiefly with children, but was over in two or three days, unless by catching cold it continued appearing and disappearing alternately for some days longer; there was no complaint of the 'Throat, and no deaths ensued. It is not the same with the sore 'Throats which are observed from time to time in some of our Country Towns, especially in the Winter season : these are Endemial and constitutional, being tumefactious and exulceratious with fluxion in the Fituces and Neck; procceding from an intense scrophulous, scorbutick, or Psorick habit (in such subjects vesications by Cantharides did putrifie) without any Eruptive fever : ours have generally an Eruptive fever or tendeney that way, so that of those who have died in Boston, not above one in seven died of any Throat ail, but of this fever. It is however observable that the Scrophulous and Psorick, are most susceptible of this distemper, and suffer more remarkably.

2. This Epidemical distemper is no creature of the Scasons, it having prevailed from May 1735, when it first emerged, the whole year or all the Seasons round. It is no produce of pcculiar climates and soils, because it bath made its appearance in various places from Pemaquid in 44 N. Lat. to Carolina Southward, and as we are lately informed, it is in our West India Islands. It is remarkable that in damp places, as near large Ponds, fresh water Rivers, woodlands, and the like, it has done the greatest exccution, as does the Rot amongst Sheep in fenny Lands.

It is not personally infecting after the rate of the Plague, SmallPox, \&c. where cvery Person is susceptible, excepting a very few anomolous constitutions. Children are the most olnnoxious to any infection; but with us several Children in the family, where the distemper appeared, have cscapel: it is true where it happens in a family, it frequently seizeth severals, as is the case with our Country Peripneumonick Fevers, and our Autumnal remitting slow Fevers, which cannot be said to be contagious. The distance in time of Infection to be supposed received from a sick Person, to the time of the distemper's appearing in the supposed infected, could never, with any rea- 
sonable allowance of latitude, be reduced to any rulc, as in Small.Pox, Measles, \&c. We have Anatomically inspected Persons who died of it with so intense a fietor from the violence of the disease, that some Practitioners could not continue in the r oom; but without being infected our selves or carrying it into ta milies. Many children without rescrve, frequent the houses and chambers of the sick, and escape. It does therefore procced from some undiscovered quality of the air, affecting only peculiar constitutions of persons and families : notwithstanding of its being generally favourable, it proves fatal to certain families; many families for this reason have buricd all or most of their children, u. g. Boynton of Newbury-Falls lost his eight children, at Hampton-Falls in 5 families dicd 27 Persons.

3. This is a very anomalous Illness, some complain a day or two before they are confined, some are seized as it were instantaneously, it is generally . most severe with these last. In some a soreness of the 'Throat and darting pain there, reaching the Ears, is previous to all other Symptoms; in others the common Symptoms of a fever appear, hefore any inflammation or specks are perceivable in the Fauces. Some have a sore Throat without any perceivable eruption, only a gentle breathing continued Sweat, or. an increased insensible perspiration with the peculiar smell of the morbid efluvia. Some (but very few) have the cuticular eruption's without any sloughs in the 'Throat; only the Tonsils, Uvula and velum Palati, tumified and inflamed; and in a few, a purulent discharge from some parts deeper than the Fauces, that is lower than the sight can reach, these are not without danger. Many of those who died early of a $\mathcal{N}$ ecrosis, had no tumefaction, inflammation or specks in the Throat.

The time of Eruption is very uncertain; in a very fow it preceeds the soreness of the 'l'hroat, in a few it goes pari passu with the affection of the Fauces; but generally it is (not much) later than the first complaints of the Throat, in a young Woman it was later by 14 days.

In ruddy complexions the eflorescence is very descernable; it is not so distinctly perceivable in Brunets, Indians, and Negroes; unless the miliary Eruption have a considerable Relievo as in some, they generally scale and peel notwithstanding. Sumetimes it appears only in the checks, sometimes only a few clusters in the extrenities. Sometimes the suffusion was scarce miliary and vanished insensibly by becoming gradually paler without scaling. Where the Miliary Eruptions were considerable, the extremities peel in scraps or strips like Exuvia ; in one or two the nails of the fingers and toes did cast 
off. The period or continuance of Eruption is sometimes prolonged by weakness of nature, by undue evacuations, or by the Patients being exposed to the cold.

4. In some who were very slightly affected, their Illness was of a much shorter continuance, than is described in the Standard kind. Most of those zoho died of the Physician died by immoderate evacuations. As to the deaths, only a few were oceasioned immediately by any distemperature of the Throat; they were generally the effoct of the Fever, either by an immediate $\mathcal{N}$ ecrosis at first seizure, or by the ordinary fatality of Fevers, or by consequential ails. In Boston at a medium of the last eight healthy years (1723. 1724. 1725. 1726. 1727. 1728. 1732. and 1733) in the Months of Ocinber, November, December, January, February, March, April to $18 \mathrm{th}$ May, died pr. an. 263 Whites and Slaves; this year in the same space of time died 382 , is 114 extra deaths, and may be reasonably charged to this Illness, it being otherways a healthy time: of these 114 , about 71 cases came to my knowledge, whereof in the first period died 35 , in the second period 28 , and of consequential ails, 8 . Of these 71 , only about 10 can be said to have died of sore Throats. Of these 71 only 9 were upwards - of 14 at. According to the nearest estimate I can make in round numbers, about 1 in 35 have died, that is about 4000 Persons in Boston have had this distemper, which is about one 4th part of the Inhabitants.

5. The Summer 1735 was unusually wet and chilly with many Easterly winds, in the Summer \& Autumn it prevail'd and was very mortal in several Country Towns. In Boston it began in Autumn but did not prevail until Winter, which was not rigid with hard frosts as is usual, but with a very disagreeable chill in the nir, especially in the Month of March last, in which Month was our greatest Mortality.

6. Wost Malignant distempers affect to throw off their malignany by some Emunclory. The despumation of this acrid inqination of the juices in our distemper, that is, its natural Crisis, seems to be by the patent and salutary Emunctories of the Fauces and skin. In corrosive taints, u. g. Venereal and others, a Mercurial ptyalism and sudorifick decoction of the woods, answer hest; this gave us the hint of promoting the tendency of nature in our. Jllness, hy Mercurials, and gentle breathing Sweats a bed; which with good management seldom fail'd, excepting where the $\mathcal{N}$ ecrosis was irremediable from the beginning.

Some affection of the Throat secms to attend most kinds of Eruptive Fevers. In the Small-Pox (even where the pustules and The New England Journal of Medicine, Surgery and Collateral Branches of Science as published by 
other Symptoms were in the smallest degree) they all complain of a soreness of the Throat, but without uk erating. In the Measles there is a hoarsness, and soreness of the Throat. In ours besides the soreness, tumefaction, and inflammation in the Fauces; there are specks or sloughs of a mellow white or Cream colour, like those on the inside of the chcelss in a Mercurial ptyalism; the Scruphulous and Venereal ulcers in the Throat are yellow; Aphthre are more of the nature of phlyctence; many of our Patients complain of a copperish taste or peppery smart in the 'Throat, as they express it.

7. As in all other distempers so in this there do somelimes happen violent Symptoms, meerly from the Regimen and Medicines used; which on that account are not of that bad consequence, as if they had procecded from the distemper in its natural

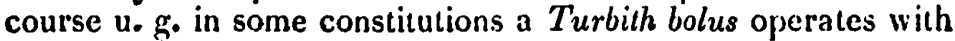
violence, so as to occasion shiverings, torsions of the Bowels, and Spasms, as if the Patient were moribund: Calomel even in very small doses seizeth the Mouth of some to a very considerable degree of inconveniency.

8. We did not observe any genuine second seizures. It is true, being Winter Season, many common sore 'Throats, that is, relaxations of the Uoula and inflammations of the Tonsils; have passed with the less observing practitioners, for the genuine Epidemick and were used accordingly; such have afterwatds had this lllness, and was erroneously called a second seizure. N. B. Our Epidemick is attended with no cough, unless when complicated with a cold or some old habitual Tissis : upon recovery, it lcaves frequently a small calarrhous colliquation or cough, but of short continuance.

In some after being well, upon catching cold, the Tonsils have been inflamed cven to suppuration; in others the Uvula and Velum Palati infiltrated and some phlyclence or common Aphthe, have appeared. Such have also by some been deem'd as second seizures, and used as such.

After a long continuance of cold chilly Weather, there set in suddenly warm Weather hot as mid Summer. May 25th, 26th, \&c. several children, who formerly had this Eruptive fever, have an efflorescence or miliary eruption by the heat, as is not unusual with children in hot weather: this was by mistake of some practitioners and others, called a second seizure.

9. No conditions of Mankind were exempled (in our Epidemical Autumnal dysertiery. . 1734. the Negroes escuped) Europeans, West-India Jslanders, Indians and Negrofs, of all :sges, were equally subject to it: but, as in most Lpidemical dis- 
eases, it affected Children and the younger Persons more generally.

10. This is a Real History of the distemper as it appeared in Boston Nezv-England, taken clinically from the life and not copied. There is no stroak or clause, but what I can vouch by real not imaginary cases. It is founded only upon observations or phonomina, that is upon the Symptomis that appeared in the course of this Epidemical disease; it must therefore be of permanent truth.

Account of some Puerperal Cases, which occurred at the Boston Almshouse during the winler of 1823-24. lisy JoHN W ARE, M.D. Physician and Surgeon to the Ilouse.

BEFORE relating the cases which form the more immediate subject of this paper, it will be proper to notice the state of health in the Almshouse, before, and during the period in which these cases took place.

In the months of October, November, and the beginning of December 1823, there occurred a considerable number of cases of simple continued fever, the duration of which was generally not less than fourteen days, and the termination tavourable, although the course of the disorder was very little, if at all influenced by medical treatment. In some instances, during convalescence, in consequence principally of improper diet, a diarrhœa took place, which in one patient proved fatal at the end of more than three months from the accession of fever, and in several others produced a long and tedious recovery.

During the winter there was among the subjects of the house a remarkable disposition to such bowel complaints as are usually met with at the latter end of summer and the beginning of autumn. From the middle of December to the middle of March they were very gènerally afficted with diarrboa, particularly so during the mild and open weather of the early part of the winter. 'This affected not merely those in whom it was the only complaint, but extended also to patients suffering. under other discases, particularly those of a chronic nature; and in these it proceetled to such an extent as to merge in itself the symptoms of the primary disease, and become the principal, or in fact, only object of attention.

The evacuations in this disorder consisted principally of undigested food, and thin mucus; though in many cases blood was mixed with these substances in considerable quantities. 